\title{
Identification Of Business Knowledge Management Strategy: Using The Research Skills Development Framework Concept
}

\author{
Ismaulina \\ IAIN Lhokseumawe, Indonesia \\ ismaulina@gmail.com \\ Sardjana Orba Manullang \\ Universitas Krisnadwipayana \\ somanullang@unkris.ac.id \\ Jemi Pabisangan Tahirs \\ UKI Toraja, Indonesia \\ tahirsjemi@gmail.com \\ Suwandi S. Sangadji \\ Universitas Nuku, Indonesia \\ Coresponding email:wandy@univ-nuku.ac.id \\ Mardhiah \\ UIN Alauddin Makassar, Indonesia \\ dhiah612@gmail.com
}

\begin{abstract}
The qualitative study discusses and guides the business people with the strategic management of business knowledge using research skills development framework. The success of the development of business strategy management is closely related to the framework of developing specific field expertise. One of them is through the research skills development framework (RSD). For that purpose, we have taken a strategic step, namely collecting data and information from various literature sources that seek and examine several scientific publications related to the framework and concepts of developing research expertise. After the data is collected, we next analyze with a phenomenological approach to ensure that our findings are valid and reliable in answering research formation questions. The analysis process involved coding the data, in-depth interpretation, and conclusions so that the findings could line up with the problems of the research. Finally, we could conclude the results that the RSD framework can be a conceptual framework in developing a business management strategy with analysis of approaches and communication assisted by rubrics and autonomy for researchers. Thus, these findings are to become part of a formal reference for starting a business that is useful and effective.
\end{abstract}

Keywords: Management business, knowledge strategy, Research Skill Developing framework.

\section{INTRODUCTION}

We certainly agree that the knowledge inherent in our employees is essential to be managed. There are even some profitable companies that consider the knowledge component a company asset as what Nonaka $\&$ Teece, (2001) said that the knowledge use within organization. Justify this and how to do the work must be based on proper knowledge. (Holste \& Fields, 2010; Möller et al., 2005; Möller et al., 2005). However, the problem is what if the existing knowledge among employees is not evenly distributed, some people are experienced or have much knowledge. However, some people still do not understand much 
about the ability they should have. Access to this knowledge must also be considered, meaning that employees do not have difficulty finding or accessing the knowledge they need. On that basis, we conduct this study so that every business owner can manage his business appropriately and effectively, especially strategies for managing employees and other resources with a specific right system such as the strategic approach having by the Research Skill Development framework.

Every important decision must be born with a very mature and honed mind because decisions made hastily will be made based on essential considerations based on existing experience and information in terms of various sources. And aspects of interest and urgency, such as knowledge sharing, which routinely studies business dynamics and demands that consumers need in an increasingly competitive era, always focus on selling only something popular and required by the consumer or target market. This decision is also based on common sense as well as strategic studies and considerations.

It has often been discussed that entrepreneurs' duty and obligation to encourage and provide the best service to customers. Because the business will go forward when customers from ordinary to loyal customers, it is not only the responsibility of customer service plus care and marketing personnel. However, this is a task that is no longer common to all parts of the corporate organization. Thus there is an excellent synergistic relationship between divisions. It is creating a stable and healthy work team that doesn't just think about their interests. Whatever the reasons why we have to decide to provide the best service to employees, it is based on the results of business quality management considerations so that service must be of a super standard so that consumers do not feel disadvantaged every time they need business goods and services in a business and mutual benefit.

It is with the mastery and application of strategic knowledge management, then each employee in a company will find it easier to adapt. Especially for all events that could result in specific changes to the business environment. Because every employee who is challenging to adapt to the conditions of the company, they will find it very difficult to manage the work given and trusted by their superiors. So it turns out that the ability to manage adaptability is also very urgent. It is essential to understand the capacity and knowledge development of every employee in every organization. Because a good understanding will be applied to different situations over and over again, this is done to develop the process of increasing production or developing company products towards profitability. Thus, Without an increase in employee productivity anywhere, it will be expelled because the company will suffer losses. After all, it employs individuals who feel unwilling to innovate to increase productivity and work motivation. As a knowledge company asset with a good source of knowledge, all employees will need additional facilities to use it. That way, the use of knowledge sources can be increased to support the creative process and develop various innovations. All employees are expected to be capable of mastering this business knowledge management. Because this is very important to improve fellow companies' competence to increase the productivity of each employee and the company itself, this issue is a prominent asset name that deserves special attention.

The definition of strategic management is often understood as a work process of analyzing and managing business strategies and applying them, and monitoring the smooth and sustainable use of companies and organizations to achieve and maintain their competitive advantage and be profitable. Strategic business management can also be defined as the art and science used to create, implement and evaluate decisions in various functions that enable an organization and a company to achieve its goals, namely profit and sustainability. With this Strategic Management, an organization or company can assess the business and industry, including evaluating its competitors and setting goals for the organization to outperform current and future competitors and then reassess each of its organizational strategies.

Branch of Management which is concerned with developing a strategic vision, setting goals, formulating and implementing strategy. By taking corrective steps for deviations to achieve organizational system has two main objectives, namely to act as a guide for the organization so that it can help the organization face various challenges in the environment business and to gain a sustainable competitive advantage to outperform its competitors who can ultimately dominate its targeted market.

Research-Based Learning is the solution. The development of research skills enables researchers to identify problems by gathering sources of information whose concepts can help solve problem 
identification, evaluating information sources for quality and related variables before finding practical solutions to problem formulations. The Research Skills Development Framework (RSD), initiated by Willison \& O'Regan, (2007), is a research learning tool used to complete the process of analyzing and planning a learning-based curriculum with guidance for the systematic development of student research skills. This research framework is descriptive, can be described, and is useful for work assignments, lectures in various majors, or educational program planning purposes.

The strength of the Research Skills Development (RSD) framework is that it is easy to implement in many study program majors both within Australia and abroad. Since its development in 2006, this framework has become a conceptual framework and non-prescriptive format based on several six core skills recommended by many institutes throughout Australia and New Zealand for Information Literacy activities based on Bloom's Taxonomy. This RSD framework can be part of improving the engaging Learning and teaching model at the University of Adelaide, South Australia. With the help of an additional detailed framework for student autonomy in enhancing student information and study skills, it is described as Prescribed, Bounded level; Unlimited scaffolded rank, open and ending, and levels. This RSD framework also has the training, workshop seminars, and consultations for study management and library information.

Another advantage of the RSD framework is its conceptuality it is easy to describe by researchers who have fewer skills so that they need to be developed and connected to acquisition skills, understanding skills, and skills in the application of all information both in the context of various social, cultural, lecture and other contexts. To produce alumni who are equipped with research competency studies to overcome future challenges is essential; it is necessary to have a structured approach to enhance various skills from an undergraduate level to doctoral programs. On that basis, we carry out this study to understand the business knowledge management strategy based on a Research Skills Development Framework.

\section{METHOD}

This study's main objective is to understand the business knowledge management strategy based on a Research Skills Development Framework Concept. To be precise, we will examine some of the published findings related to previous studies' evidence if this RSD is suitable for measuring business knowledge management strategies, especially in coaching employees as company assets. To make it easier for us to understand, we have done a series of data collection, including searching with search engines, observation, and documentation. After the data is collected, we then analyze it with an abstract pattern of research skills development framework, namely the Inquiry facet or Embark, Find and Generate, evaluate and reflex, organize, analyze and communicate information. After the analysis stage, we finally concluded that the ten publications we studied had shown the suitability of the information to the needs of the business knowledge management strategies in several companies that were our study's objectives. Thus our findings will be useful and become a reference for scientific development and capacity building of company employees.

\section{RESULT}

J. W. Willison, (2012) as a successful initiator, studied how to integrate the RSD framework into the university curriculum. This study developed the results of 27 academics by explicitly honing and evaluating research skills in 28 normal even semester subjects. These programs range from 17 students to a middle class of 222 students and reach programs from the first semester to major in economics, engineering, medical, humanities, and science masters programs at five universities in three states in Australia. The results of the academic review show that the stages of developing students' research skills are explicit. It is about increasing student resources, helping many academics to describe development goals, and enabling students to provide more contributive input to students who have been involved in developing academic potential before changing their perceptions of business strategy knowledge-building strategy. 
Akter et al., (2016) noted how to increase company achievement through essential data analysis skills and business strategy relevance. Much interest in big data has recently enabled companies to develop business strategy skills to increase company productivity. (Mikalef et al., 2018; Wang et al., 2018). However, this development still benefits several large companies. Very few appear to be able to achieve a significant impact through big data. This study tries to look at a model taken from the resourcebased theory and the attachment of socio-materialism views to solve these challenges. His findings point to this development as a model for strategy development.

Bell et al., (2004) explored the correlation between the whole business strategy knowledge management of each firm and the opportunity to go international. (M. V. Jones et al., 2011; D. C. Jones et al., 1998). Adopted a qualitative approach, the study involved semi-structured interviews with key global corporate decision-makers based in the three London regions. Their findings indicate strategic knowledge management policies, including those related to ownership and changes in corporate HR management, by having an essential role in the internationalization of human resources from many companies. The finding of a close relationship between market-focused management policies, and business product or process innovation often provides an essential stimulus for international expansion.

Magnier-Watanabe \& Senoo, (2010) suggested that efforts shape knowledge management in the organization and culture of the nation confirm the quantitative finding before. Their study of the characteristics of strategic organizational management changes knowledge management in organizations. It assesses whether the national management culture of employees has the same knowledge of changing knowledge management. Although the organizational characteristics and management culture were found to influence the direction of knowledge acquisition, the findings show that the typical company characteristics are the main prescriptive aspects which are more strongly compared with the knowledge management culture. A study approach with qualitative methods first explains this framework that connects company characteristics and national management culture with knowledge management. It has now been expressed with a quantitative approach. Among the assumptions about knowledge management outside the organization that actions are not necessary within the company, the data prove that organizational characteristics have a more significant impact than knowledge management.

Boardman \& Ponomariov, (2014) discusses how researchers organize and manage groups of researchers from various fields of science to research in universities. The result of this paper is that the centre which has management knowledge should meet within the core researchers themselves and with colleagues and subordinates with experience in various organizations, business management training centres and professional experience that will convey unique systematic and managerial characteristics. When it matched with centre without business management knowledge from interviews and documents to sample studies aimed at serving such US science foundations is so essential. The study understands organization and management as a function of operational and business management knowledge types. The implications of this study are to overcome future challenges so that the science and knowledge team in higher education research centres and comparable settings have been successfully discussed. (Council, 2014; Leahey, 2016; Mangematin et al., 2014).

Berciu \& Bhatt, (2001) since 2001 has studied knowledge management in corporate business. He investigates the interactions between technology, efficiency, and people. In the journal of knowledge management, it is found that knowledge management processes can be grouped into activities of creating knowledge and job skills, validating knowledge, sharing knowledge, sharing of experience, and application of knowledge. To be able to take advantage, he explored experience, in several organizations that quickly balance the activities of each knowledge management. In particular, he balances that require effort in a knowledge culture, cutting edge technology, and type of organization. A number of the companies he studied believe there will be a point of focus specifically on HR, the latest technology, or knowledge process techniques. They all manage knowledge to the will of the employees. However, any exclusive focus on human resources, technology and money, or engineering does not allow the company to continue its competitive advantage because the reason for HR management development is not restarting. 


\section{DISCUSSION}

Management of business knowledge strategy or knowledge management is essential for every company because knowledge management functions as a measurable and strategic approach to ensure that adequate knowledge of company goals can continue. Business strategic knowledge management is a concept that has been developed since the 1990s when academics presented innovative ideas about this discipline of knowledge. One of their goals was that initially, business knowledge management used company practices and technology to take advantage of company advantages. Business knowledge management systems are focused on the willingness and ability to gain experience in a scalable network and make it more comfortable in the future.

However, since this first step, it has been less successful, and at first, many business organizations have abandoned knowledge Management. However, enterprise 2.0 has brought new life to business knowledge management, thanks to a shift in focus from knowledge itself to individuals who hold, share and use collaboration and innovation knowledge. In some ways, new practices and technologies introduced by corporate social partnership have shifted perspectives on how to harness employee knowledge through new models for collaborating, sharing, and using knowledge. This network effect allows connecting people to share knowledge, making that knowledge more accessible.

From other sources, it is also stated that Knowledge Management is a form of appreciation for knowledge assets in a company because only then can a company manage these hidden assets. We know, a company certainly has a variety of investments, there are also several items, peripherals to ticks, all of these assets are grouped right. Become a company valuable object that can be calculated. However, it is not uncommon to find companies that are run by a series of human resources which sometimes keep changing every year forget to mention that HR and knowledge are critical assets. It could be from a meeting, from a proposal, from several things that have happened so that everything that has been running and is successful can be said to be a company that is already sustainable. Well, the question is, when some of the human resources have been designed for several years, some have changed with new HR, of course, the experience and knowledge are different.

So, when companies in future experience problems due to a change in their human resources, they are not confused. Because the company/organization is like a band group, each person has their character, which is the name of each. These characters do not always match each other. So, to make beautiful music, of course, need adaptation to each other, need harmony, the closeness between personnel and also their skill, when the piece has been successfully executed and then suddenly the personnel leave what will happen. Confused, we can indeed find new personnel, but not necessarily suitable to play as beautifully as before, right? It takes more adaptation time until finally, we can see the gap again, here it is Knowledge Management helps, recording the traces that have been produced by senior personnel so that later the existing tracks can also be used as a success guide for new personnel.

\section{Why is RSD important in developing business strategy management?}

The answer is that RSD is a strategy that is an essential key to the success of a company and can even be a competitive advantage. Along with the ever-changing changes in industry and market, RSD is becoming more and more needed. Research needs to be done to determine changes in customer preferences; then, the company will conduct further research on how products and designs are suitable for their customers. RSD enables innovation, which in turn gives the company a competitive edge in its industry. The advantage of RSD is due to intense research, making the products and services provided according to customer needs. Vital research also allows companies to have qualified technicians to produce superior outcomes in their industry.

Large companies usually do not hesitate to invest heavily in RSD because they expect significant returns. An example is a pharmaceutical company that is very intensive in carrying out RSD. The risk of failure is enormous, but if RSD manages to produce a successful medicinal product, the payoff is considerable. However, RSD is not only about developing superior products, but also researching and 
developing new markets and marketing techniques. For example, in the 80s, once giants like IBM, Apple, HP and Compaq led the market. Among them, all spend billions of dollars to produce superior products and sophisticated production techniques. However, then the PC industry was defeated by Dell, which offered a very different marketing method, namely direct selling, where Dell immediately sold to the home and came to the home or office to repair a damaged PC.

So, the point is not only product research and development that must be considered, but also research on market opportunities, marketing techniques. In general, the company's RSD ratio in the US is about $3.5 \%$ of revenue. However, for high-tech companies such as computer manufacturers, the RSD budget can be as high as 7\%. In fact, for several well-known pharmaceutical companies such as Merck or Novartis, their RSD budget could be around 15\%. More than $90 \%$ of surveyed company executives consider innovation very important because it is done in preparation for global economic recovery.

\section{CONCLUSION}

We can conclude that the study's findings entitled "Identification of Business Knowledge Management Strategy: Using the Research Skills Development Framework Concept. " The results of many successful publication studies have sharpened the use of research skills development as a framework that can help develop sources of knowledge in the business management sector and companies, large and small. On average, they strongly support our results that strategic management of business developers can be developed by applying various research concepts and developments. Our findings are that the RSD framework can be a conceptual framework in creating a business management strategy with analysis of approaches and communication assisted by rubrics and autonomy for researchers. Thus, these findings are to become part of a formal reference for starting a good and useful business.

\section{REFERENCE}

1. Akter, S., Wamba, S. F., Gunasekaran, A., Dubey, R., \& Childe, S. J. (2016). How to improve firm performance using big data analytics capability and business strategy alignment? International Journal of Production Economics, 182, 113-131.

2. Bell, J., Crick, D., \& Young, S. (2004). Small firm internationalization and business strategy: An exploratory study of 'knowledge-intensive'and 'traditional'manufacturing firms in the UK. International Small Business Journal, 22(1), 23-56.

3. Berciu, M., \& Bhatt, R. N. (2001). Effects of disorder on ferromagnetism in diluted magnetic semiconductors. Physical Review Letters, 87(10), 107203.

4. Boardman, C., \& Ponomariov, B. (2014). Management knowledge and the organization of team science in university research centers. The Journal of Technology Transfer, 39(1), 75-92.

5. Council, N. R. (2014). Convergence: Facilitating transdisciplinary integration of life sciences, physical sciences, engineering, and beyond. National Academies Press.

6. Holste, J. S., \& Fields, D. (2010). Trust and tacit knowledge sharing and use. Journal of Knowledge Management.

7. Jones, D. C., Abbey, B. B., \& Cumberland, A. (1998). The development of display rule knowledge: Linkages with family expressiveness and social competence. Child Development, 69(4), 1209-1222.

8. Jones, M. V., Coviello, N., \& Tang, Y. K. (2011). International entrepreneurship research (19892009): A domain ontology and thematic analysis. Journal of Business Venturing, 26(6), 632-659.

9. Leahey, E. (2016). From sole investigator to team scientist: Trends in the practice and study of research collaboration. Annual Review of Sociology, 42, 81-100.

10. Magnier-Watanabe, R., \& Senoo, D. (2010). Shaping knowledge management: Organization and national culture. Journal of Knowledge Management.

11. Mangematin, V., O’Reilly, P., \& Cunningham, J. (2014). PIs as boundary spanners, science and market shapers. The Journal of Technology Transfer, 39(1), 1-10. 
12. Mikalef, P., Pappas, I. O., Krogstie, J., \& Giannakos, M. (2018). Big data analytics capabilities: A systematic literature review and research agenda. Information Systems and E-Business Management, 16(3), 547-578.

13. Möller, K., Rajala, A., \& Svahn, S. (2005). Strategic business nets-Their type and management. Journal of Business Research, 58(9), 1274-1284.

14. Nonaka, I., \& Teece, D. J. (2001). Managing industrial knowledge: Creation, transfer and utilization. Sage.

15. Wang, Y., Kung, L., Wang, W. Y. C., \& Cegielski, C. G. (2018). An integrated big data analytics-enabled transformation model: Application to health care. Information \& Management, 55(1), 64-79.

16. Willison, J., \& O'Regan, K. (2007). Commonly known, commonly not known, totally unknown: A framework for students becoming researchers. Higher Education Research \& Development, 26(4), 393-409. https://doi.org/10.1080/07294360701658609

17. Willison, J. W. (2012). When academics integrate research skill development in the curriculum. Higher Education Research \& Development, 31(6), 905-919. 